\title{
Searching for CAR modulators
}

Paavo Honkakoski, Ph.D., Professor in Biopharmacy

School of Pharmacy

Faculty of Health Sciences

University of Eastern Finland 


\section{Searching for CAR modulators}

\section{Paavo Honkakoski}

School of Pharmacy, University of Eastern Finland

Yliopistonranta 1C, FI-70210 Kuopio, Finland

Telephone: +358403552490

E-mail:_ paavo.honkakoski@uef.fi

ORCiD: $\quad$ 0000-0002-4332-3577

Number of text pages:

Number of Tables:

Number of Figures:

Number of references:

Word count in Abstract:

Word count excluding references:

Keywords: nuclear receptor CAR, activation, translocation, agonist, in vitro, assay strategy 


\section{Abbreviations}

AhR, aryl hydrocarbon receptor; CAR, constitutive androstane receptor; CITCO, 6-(4chlorophenyl)imidazo(2,1-b)(1,3)thiazole-5-carbaldehyde O-(3,4-dichlorobenzyl)oxime; CYP, cytochrome P450; DMSO, dimethyl sulfoxide; EGF, epidermal growth factor; ERK, extracellular signal-regulated kinase; LBD, ligand-binding domain; LBP, ligand-binding pocket; MAPK, mitogen-activated protein kinase; NRF2, nuclear factor erythroid 2-related factor 2; PP2A, protein phosphatase 2A; PK11195, 1-(2-chlorophenyl)-N-methyl-N-(1methylpropyl)-3-isoquinoline carboxamide; PB, phenobarbital; PPAR, peroxisome proliferator-activated receptor; PXR, pregnane X receptor; RAR, retinoid acid receptor; RXR, retinoid X receptor; TCPOBOP, 1,4-bis-[2-(3,5-dichloropyridyloxy)]benzene. 


\begin{abstract}
The constitutive androstane receptor (CAR; NR1I3) has been established as one of the main drug- and xenobiotic-responsive transcriptional regulators, collectively called xenosensors. CAR activates the expression of several oxidative, hydrolytic and conjugative drugmetabolizing enzymes and drug transporters, and therefore, it contributes to drug and xenobiotic elimination, drug interactions, and toxicological processes. This minireview introduces mechanisms that modulate CAR activity and focuses on the recent approaches used to search and characterize CAR agonists, inverse agonists and indirect activators. This minireview is dedicated to Dr. Masahiko Negishi to celebrate his scientific achievements during his long service at the National Institutes of Health.
\end{abstract}

\title{
Significance statement
}

Discovery and characterization of human CAR modulators is important for drug development, toxicity studies and in generation of chemical tools to dissect biological functions of CAR. This minireview focuses on the main methods used to search for these compounds and discusses their essential features. 


\section{Introduction}

The constitutive androstane receptor (CAR; NR1I3) is one of the key drug- and xenobioticsensitive regulators of enzymes and transporters important for drug metabolism, disposition, interactions and toxicological outcomes along with the related pregnane $\mathrm{X}$ receptor (PXR; NR1I2) and the aryl hydrocarbon receptor (AhR). Additionally, CAR participates in the metabolism of glucose, lipids and bile acids, and has a role in cell-cell communication, cell cycle and chemical carcinogenesis. Searching the PubMed database in October 2021 with the phrase "constitutive androstane receptor OR nrli3" yielded over 1560 publications, an increase of $\sim 700$ papers after our earlier review in 2013 on CAR properties and actions (Molnár et al., 2013).

The readers are referred to recent reviews (Table 1) that cover many aspects of CAR properties and its involvement in biology. These reviews are highly recommended reading for those seeking specific information on the CAR protein and its functions. In this minireview, I will focus on the key aspects of human CAR structure that affect its activity, current approaches used to search and characterize human CAR modulators, provide some examples of novel compounds, and highlight important issues associated with these studies.

\section{Brief historical perspective}

Human and mouse CAR were initially described as constitutively active nuclear receptors (NRs) by David Moore's laboratory (Baes et al., 1994; Choi et al., 1997) but true target genes were unknown at that time. Work on the phenobarbital (PB) induction of mouse Cyp $2 b 10$ gene expression by the Negishi group defined the PB-responsive enhancer module that was activated by multiple cytochrome $\mathrm{P} 450$ (CYP) inducers and CAR/retinoid X receptor (RXR) as the crucial heterodimeric transcription factor translocating from the cytoplasm into the 
nucleus (Honkakoski et al., 1997, 1998a, 1998b; Kawamoto et al., 1999). Anecdotally, we submitted our seminal publication (Honkakoski et al., 1998a) first to the Nature journal, which declined it on the grounds that we should have demonstrated the direct binding of PB to CAR to gain acceptance for this manuscript. In hindsight, the editors were asking for the moon, because this is not the actual mode of PB action that was finally elucidated some 15 years later (Mutoh et al., 2013).

Subsequent reports showed that mice lacking CAR could not induce CYPs, increase liver size nor enhance tumor promotion in response to PB exposure (Wei et al., 2000; Ueda et al., 2002; Yamamoto et al., 2004). Concurrent characterization of PXR as the main regulator for CYP3A expression (Kliewer et al., 1998) established these sister receptors as key controllers of drug metabolism and disposition (Willson and Kliewer, 2002; Yan and Xie, 2016).

Diverse chemical classes including pesticides, fire retardants, environmental contaminants, drugs, and industrial chemicals are now known to bind to or modulate human and animal CAR activity in cell-free and cell-based assays (Table 2; Molnár et al., 2013; Chai et al., 2016; Lynch et al., 2019; Küblbeck et al., 2020). However, some compounds such as PB, bilirubin, phenytoin and teriflunomide (Mackowiak and Wang, 2016; Carazo et al., 2018) are CYP inducers without any apparent binding to or activation of CAR in cell-based reporter gene assays. These indirect activators can translocate CAR from the cytoplasm into the nucleus (Figure 1). At least for PB, this involves inhibition of the epidermal growth factor (EGF) receptor, participation of mitogen-activated protein kinase (MAPK) and extracellular signal-regulated kinase (ERK) pathways, and cytoplasmic protein phosphatase 2A (PP2A)mediated dephosphorylation of CAR at residue T38 in the cytoplasm prior to translocation and target gene activation (Mutoh et al., 2013; Negishi et al., 2020). However, this process is poorly understood for many compounds listed as indirect activators. 
The overlapping ligand preferences (Chai et al., 2016; Lin et al., 2020) and shared CYP target genes (Li et al., 2015; Ochsner et al., 2016) of CAR and PXR make it difficult to ascertain which receptor is responsible for CYP induction in primary hepatocytes and in vivo. Moreover, CAR modulators have additional targets that may influence CYP induction and other drug disposition processes independently of CAR. For instance, recent reviews indicate that pesticides, phthalates and flame retardants often activate CAR, PXR and peroxisome proliferator-activated receptors (PPARs), and bisphenols modulate CAR, PXR and steroid hormone receptors (Küblbeck et al., 2020; Toporova and Balaguer, 2020). Flavonoids that are either indirect or direct CAR activators (Chai et al., 2016; Yao et al., 2010) are also e.g. inhibitors of the MAPK, ERK or EGF signalling and activators of nuclear factor erythroid 2related factor 2 (NRF2) (Yahfoufi et al., 2018; Hazafa et al., 2021; Clifford et al., 2021). These issues complicate the search strategies to identify true CAR modulators and require multiple different assays for the correct assignment of their mechanism of action.

\section{Structural features that contribute to high constitutive activity and agonism of CAR}

So far, only three agonist-bound and one inverse agonist-bound CAR/RXR ligand-binding domain (LBD) crystal structures from early 2000's exist (Buchmann et al., 2018). Despite advances in molecular modeling, this limits our understanding of mechanisms for CAR modulation. The high constitutive activity of CAR is due to stabilization of the helix H12 in the active position (Figure 2) that allows coactivator binding by three mechanisms. First, an additional LBD helix X forces the short H12 towards the active position (Xu et al., 2004). Second, the residues F161, N165, F234 and Y326 shield the ligand-binding pocket (LBP), preventing in most cases the direct interaction between the agonist and H12, but providing further H12 stabilization at the same time (Xu et al., 2004; Molnár et al., 2013). Third, the interface for CAR/RXR dimerization (comprised of helices 7, 10 and 11 in Figure 2) is larger 
than in most NRs, and RXR binding seems to stabilize CAR LBD in the active conformation (Suino et al., 2004). All three interactions increase the coactivator recruitment in the absence of ligands, and thus, create difficulties in detecting responses elicited by CAR agonists.

The observed CAR LBP volumes $\left(525-675 \AA^{3}\right.$ ) can accommodate various ligands that employ mostly hydrophobic and some hydrogen-bonding interactions within the LBP-lining residues. In human CAR structures, co-crystallized agonists do not interact with H12 like the mouse CAR does with its specific agonist 1,4-bis-[2-(3,5-dichloropyridyloxy)]benzene (TCPOBOP) (Molnár et al., 2013). Due to the lack of other agonist-bound and ligand-free CAR structures, a comprehensive and mechanistic view of agonist-elicited changes in coactivator recruitment is still missing. The developments in computing power, molecular docking and molecular dynamics simulations may help address these gaps (Kato, 2020). It is likely that these in silico methods will not be discriminating enough to quickly and reliably detect and distinguish between all CAR agonists and inverse agonists, but they are valuable as supportive tools either for pre-selection before or mechanistic binding evaluations after the functional assays (e.g. Küblbeck et al., 2011a, 2011b; Lynch et al., 2013; Keminer et al., 2019) that will be described below.

\section{Activation differences among CAR isoforms and variants}

Alternative splicing produces multiple human and primate CAR splicing isoforms (Lamba et al., 2004; Mbatchi et al., 2018), which are not present in rodents. An abundant human transcript $(\sim 50 \%)$ encodes the wild-type CAR1 that displays high basal activity while the minor isoform CAR2 ( 10\%) and the abundant CAR3 ( 40\%) have low constitutive activity, likely due to their reduced interaction with RXR and resulting weaker binding to DNA and coactivators (Auerbach et al., 2005; 2007). In addition, some CAR activators such as 
phthalates, antivirals and artemisinin derivatives appear to display some isoform selectivity (Auerbach et al., 2005; Auerbach et al., 2007; DeKeyser et al., 2011; Burk et al., 2012; Paul et al., 2013; Sharma et al., 2015). These differences in CAR basal and ligand-dependent activity may be explained by the structural changes near the RXR heterodimerization surface (CAR3; insertion of APYLT which likely destabilizes RXR binding) or the LBP (CAR2; insertion of SPTV), respectively. Both CAR2 and CAR3 are highly dependent, unlike CAR1, on inclusion of RXR in trans-activation assays.

The gnomAD database (Karczewski et al., 2020) lists hundreds of rare single nucleotide human CAR variants $(<0.1 \%$ allele frequency) with unknown functionality. In vitro characterization has been done only for few rare naturally occurring variants: LBD variants H246R and L308P lead to complete inactivation or reduced reporter activity, respectively (Ikeda et al., 2005). I281T, which is also near the RXR heterodimerization surface, reduces the interaction with coactivators and dampens the activation elicited by weaker agonists (Prantner et al., 2018). More common non-coding or silent CAR variants are associated with drug plasma concentrations and/or adverse effects (Mbatchi et al., 2018) by yet unknown mechanisms that may include changes in CAR expression.

\section{Species differences in CAR activation}

Mammalian CAR genes have undergone positive selection that has resulted in only $72 \%$ sequence similarity between the mouse and human CAR LBDs (Reschly and Krasowski, 2006). Such divergent evolution explains the wide variability in the chemicals' ability to activate CAR and induce CYPs between species. For examples, 6-(4-chlorophenyl)imidazo[2,1-b][1,3]thiazole-5-carbaldehyde O-(3,4-dichlorobenzyl)oxime (CITCO) and TCPOBOP are potent species-selective agonists for the human and mouse CAR, respectively. 
Androstenol is a stronger inverse agonist for mouse than human CAR (Molnár et al., 2013; Chai et al., 2016), rat CAR is activated by clotrimazole to greater extent than the dog CAR (Omiecinski et al., 2011) while the opposite is true for artemisinin (Pinne et al., 2016), and triphenyl phosphate derivatives show opposing characters between the mouse and human CAR (Honkakoski et al., 2004). Different sizes and contacts of the LBP-lining residues with ligands are the likely determinants for these species differences: human CAR residues that confer species-specific responses to TCPOBOP (M340) and to 17 $\alpha$-ethinylestradiol, an inverse agonist for human CAR and a partial agonist for mouse CAR (F243), have been identified (Jyrkkärinne et al., 2003, 2005). Bovine CAR has two mutations at critical residues for CAR function (N165I, Y326F) that may explain its low responsiveness to both human and mouse CAR ligands (Küblbeck et al., 2016). Similarly, rat CAR (F234E, F243I) and dog CAR (F161L) have mutations among these key residues. However, these or other amino acid differences have not been probed between multiple species nor verified by mutagenesis.

\section{Strategies in identifying CAR modulators}

Most commonly, the search for CAR modulators begins by using assays (Table 3) that measure ligand-dependent CAR-mediated activation of reporter gene in transiently or stably transfected cells (Raucy and Lasker, 2013). There is a continuing debate about pros and cons of using either the full-length CAR or its LBD as a GAL4 fusion protein in the reporter assays. The former is more representative of the natural CAR/RXR heterodimer binding to its target DNA enhancer while the presence of other NRs may interfere with this process (Mäkinen et al., 2002). Using the CAR LBD as a fusion protein in the hunt for CAR agonists eliminates this problem and, in addition, may avoid phosphorylation-dependent effects due to omission of the residue T38 within the DNA-binding domain. Regardless of the assay type, increased reporter activity by test compounds is hard to detect due to the spontaneous 
translocation of CAR into nucleus and its high constitutive activity in continuous cell lines. Initially, inverse agonists were easily recognized but repression or no effect was observed for compounds that later turned out to be CAR agonists (Moore et al., 2002).

The problem of high constitutive activity has been dealt with several ways. First, addition of CAR inverse agonist such as 1-(2-chlorophenyl)-N-methyl-N-(1-methylpropyl)-3isoquinolinecarboxamide (PK11195) (Lynch et al., 2019) or androstanol (Sueyoshi et al., 1999; Auerbach et al., 2007) decreases the basal reporter level. The observed increase in reporter activity by the test compound is interpreted as agonistic competition for binding to the LBP that result in gene activation. This set-up is reasonable for detection of stronger CAR agonists but there is some risk of misclassification for compounds that bind weakly. Depending on the relative affinities to CAR between the inverse agonist and partial/weak agonists, the latter compounds may not be easily detected. In addition, true but less potent inverse agonists can be defined as weak agonists.

The second approach relies on the use of natural (CAR3; Keminer et al., 2019; Skoda et al., 2020) or artificial CAR variants where the basal activity is reduced by addition of amino acids to the human (Chen et al., 2010; Imai et al., 2013; Kanno et al., 2010) or animal CAR LBDs (Omiecinski et al., 2011; Pinne et al., 2016). This approach carries the risk of affecting selectivity of the LBP (CAR2 or insertions near H12) or the CAR/RXR binding (CAR3 or insertion of single alanine instead of APYLT) that may affect the ligand-dependent changes in coactivator recruitment.

Because ligand responses can vary depending on available cellular coactivators, the third approach is to find an appropriate cell line and culture conditions that allow direct measurement of CAR1 activity without addition of inverse agonists or modification of its amino acid sequence. Our laboratory has consistently detected clotrimazole as a partial CAR1 
agonist in validated assays in C3A cells (Küblbeck et al., 2008; 2011a) while other reports found it either inactive in COS-1 (Chen et al., 2010; Omiecinski et al., 2011) or an inverse agonist in CV-1 and HepG2 cells (Maglich et al., 2003; Auerbach et al., 2007). Similar assignment differences have been published for meclizine (Huang et al., 2004; Lau et al., 2011). Clotrimazole has repeatedly shown to be a CAR3 agonist (Chen et al., 2010; Omiecinski et al., 2011; Keminer et al., 2019; Toporova et al., 2020). Given the very high similarity of CAR1 and CAR3 LBPs and their similar activation profiles (Keminer et al., 2019), the above discrepancies are likely due to assay-related reasons.

The dynamic range of the employed reporter assays, as defined by the maximal response of established positive controls such as TCPOBOP or CITCO relative to the DMSO vehicle, varies significantly. These values range from about two-fold (Yao et al., 2010; Wahlang et al., 2014; Hardesty et al., 2018), to 5-fold (Mäkinen et al., 2003; Lynch et al., 2019) and to 21-fold (Küblbeck et al., 2011a) with CAR1, and between 6- to 26-fold with CAR3 (Skoda et al., 2020; Keminer et al., 2019). A low dynamic range may limit the sensitivity to detect true activators, and more importantly, observed lack of reporter activity in a suboptimal assay does not indicate discovery of an indirect CAR activator.

Finally, because compounds may influence reporter gene activity independent of CAR, it is essential to conduct control studies in its absence. These control experiments can show if the reporter activity is modulated by e.g. physicochemical interference by the test chemical (Dahlin et al., 2015) or by inhibition of e.g. luciferase or other reporter activity (Ho et al., 2013; Poutiainen et al., 2013). Other potential interferences include inhibition of cellular protein kinases necessary for CAR activation or binding to the heterodimer partner RXR for which CAR2 and CAR3 are dependent on, as recently described for retinoids (Keminer et al., 2019). Naturally, any issues with cytotoxicity or solubility of the compounds should be taken into account with cell-based assays. 
Even if the above criteria for the assay are met, the search may still fail. My first project after returning from the post-doctoral period at NIEHS was to isolate the endogenous small molecule thought at that time to keep CAR inactive, similarly to androstenol (Forman et al., 1998). We fractionated liver extracts from untreated mice and isolated fractions with potent suppressive activity. Much to our dismay, these compounds turned to be man-made lubricants (Honkakoski et al., 2004) while androstenol and related steroids were present in only trace amounts.

After the primary screen with reporter gene assays, evidence for direct binding to CAR is required. Usually, this comes from various two-hybrid assays that measure the agonist- or inverse agonist-dependent interaction of CAR LBD with a selected coactivator or corepressor peptide, respectively (Chai et al., 2019). A typical format is the mammalian 2-hybrid system in which the CAR LBD is fused with a strong transactivation domain such as VP16, the coregulator peptide is linked to the GAL4 DNA-binding domain (Küblbeck et al., 2011a, $2011 b$ ), and their ligand-dependent interaction enables activation of reporter gene expression. This assay type is quite sensitive in identifying weak or partial agonists that may recruit either type of coregulator to the CAR LBD as shown for clotrimazole (Mäkinen et al., 2003; Jyrkkärinne et al., 2005). However, if a certain ligand shows preferential binding for distinct coregulators, then it may miss detection. Another variation, halfway between a reporter gene and a two-hybrid assay, is the so-called assembly assay that detects ligand-enhanced association between the CAR helix H1 and rest of the LBD (Hoffart et al., 2012; Carazo Fernandes et al., 2015) but it cannot separate between agonists and inverse agonists. The same two-hybrid approach is also popular with recombinant proteins produced in vitro and used on assays such as the fluorescence resonance energy transfer where the CAR LBD and the coregulator peptide are labelled with distinct fluorophores (Lau et al., 2011; Carazo 
Fernandes et al., 2015) or the coregulator arrays (Murayama et al., 2014; Hsu et al., 2016). The latter system allows for parallel interrogation of ligand-elicited interactions of NRs with over 150 coregulator peptides at the same time. Other platforms include e.g., surface plasmon resonance (Rezen et al., 2017; Cherian et al., 2018), ligand-induced limited proteolysis (Küblbeck et al., 2011a; Keminer et al., 2019) and thermal stability (Cherian et al., 2018; Kobashigawa et al., 2021) assays that are label-free and measure the interaction between the test chemical and CAR LBD as ligand-induced changes in optical properties of the immobilized receptor, in susceptibility to protease degradation, and in protein heat denaturation, respectively (Chai et al., 2019). Because these assays are cell-free, they do not suffer from cytotoxicity or major solubility issues. However, they do not easily distinguish between agonists and inverse agonists unless a coregulator peptide is linked to the CAR protein (Kobashigawa et al., 2021). All utilize one form of CAR LBD fusion proteins, and non-specific binding by lipophilic test compounds tested at high concentrations may become a problem (Küblbeck et al., 2011a; Keminer et al., 2019). In addition, recombinant CAR protein tends to be quite unstable (Kobashigawa et al., 2021) that may limit the lifetime and performance of the preparation and require carefully controlled experiments.

Because CAR is retained in the cytoplasm of unexposed hepatocytes and accumulates into nucleus after treatment of both direct and indirect activators, researchers have used adenovirus-mediated transduction of fluorescently tagged CAR into primary hepatocytes as a tool to mimic this process ( $\mathrm{Li}$ et al., 2009). This allows for quick visualization of potential CAR modulators regardless of the mechanism (Mackowiak et al., 2019). Because many inverse agonists seem to produce the same response, this assay should be complemented with other experiments to separate them from true agonists. In addition, subtle differences among CAR agonists are not easily discernible due to variation in morphology and fluorescence 
intensity among hepatocytes and comparisons between test compounds requires the use of automated imaging systems (Mackowiak et al., 2019).

As mentioned earlier, the co-expression, common target genes and ligand sharing by CAR and PXR complicates identification of true human CAR modulators in primary hepatocytes or in vivo. Knockout and humanized CAR and PXR animals (Scheer and Wolf, 2014; Skoda et al., 2020) can assist in dissection and verification of CYP induction process. A similar and very promising approach is the generation of human HepaRG knockout cell lines which do not express CAR or PXR. Treating wild-type and knockout HepaRG cells with the test compounds enables large-scale identification CYP inducers and NRs recognizing them in a more physiological context than the reporter gene assays (Li et al., 2015; Preiss et al., 2021). Another option is the use of antisense oligonucleotides to down-regulate CAR expression in hepatocytes (Nudischer et al., 2020). Because all CAR inverse agonists tend to activate PXR (Table 2; Küblbeck et al., 2011b; Jeske et al., 2017; Mackowiak et al., 2017), their use is cautioned as they complicate the analysis of agonist-elicited increases in CYP expression.

\section{Some examples on identification of novel CAR ligands}

Combinations of assays have been applied to detect many novel CAR ligands and their mechanisms of action. The earlier reviews have already detailed many classes of CAR modulators (Table 2; Molnár et al., 2013; Chai et al., 2016; Marx-Stoelting et al., 2020; Küblbeck et al., 2020), so the remainder of this minireview will focus on presenting the main approaches, some novel compounds identified and difficulties encountered in these studies.

Many drug candidates and insecticides show induction of CYP2B isoforms, liver hypertrophy and tumor formation in rodents that are associated with CAR activation (Lake, 2018; Bae et al., 2021). To evaluate their relevance for humans, comparative CYP mRNA induction 
studies in wild-type, CAR null or humanized mice are first conducted. This is often followed either by reporter gene assays or RNA interference in rodent and primate/human hepatic cells to evaluate participation of CAR in this process, as recently shown for e.g. the synthetic pyrethroid momfluorothrin and the antidepressant drug candidate basimglurant (Okuda et al., 2017; Nudischer et al., 2020). Liver hyperplasia and increased DNA synthesis are not usually detected in human-derived systems while CYPs are induced.

Recent studies have shown the power of high-throughput tiered assay platforms to identify novel CAR modulators. First, screening of the Tox 21 10K library in 1536-well format with a stable CYP2B6-hCAR HepG2 cell line and suppression of the basal CAR activity with 0.75 $\mu \mathrm{M}$ PK11195 identified yielded $\sim 15 \%$ active CAR activators, $8 \%$ inconclusive and $78 \%$ inactive compounds (Lynch et al., 2019). Twenty-four most potent compounds were tested for PXR activation, and eight CAR agonists were carried forward to studies of CYP2B6 mRNA inducibility in human primary hepatocytes. Among these, neticonazole, diphenamid, phenothrin, and rimcazole increased CYP2B6 expression and translocated tagged human CAR into the nuclear compartment. Although most of the selected CAR agonists were also PXR agonists, rimcazole appeared rather selective for human CAR (Lynch et al., 2019). Another large screen was done in 293 cells transiently transfected with CAR3 and RXR expression vectors and a CYP3A4 reporter gene. This resulted in 66 hits with at least twofold activation from 2054 compounds (Keminer et al., 2019). Among ten chosen chemicals, five were previously recognized CAR modulators. It is notable that two retinoids positive in this assay were activators also in the absence of CAR3. This suggests that their activity was dependent on RXR or cellular RAR, highlighting again the need for good controls. In followup studies, clemizole, mitotane and sulconazole translocated CAR1 into nucleus and induced CYP2B6 mRNA in human primary hepatocytes. These compounds promoted SRC1, SRC3 or DRIP205 coactivator binding with CAR1 or CAR3 LBDs to very variable extents, which 
demonstrates the risks in relying on a single coactivator in two-hybrid assays. Clemizole tended to be the strongest recruiter of coactivators and the only compound that interacted with CAR1 protein in vitro. Again, all three compounds were PXR agonists indicating the difficulty in finding specific CAR agonists. Moreover, apomorphine and phenelzine that were earlier classified as CAR1 actives (Lynch et al., 2015) turned out to be inactive (Keminer et al., 2019). These discrepancies were assigned to the use of different inverse agonists to suppress the basal activity between these two screening studies.

The nuclear translocation assay (Mackowiak et al., 2019) identified 86 translocation-positive compounds while the overlap with modulators of CAR activity was less than perfect. Only $45 \%$ of identified CAR agonists showed translocation, and $58 \%$ of translocators were either inconclusive or suppressed the CAR1 activity. A retrospective analysis of literature for CYP2B6 or CYP3A4 mRNA induction indicated that among 34 translocation-positive compounds, 31 displayed CYP induction while about $42 \%$ of the translocation-negative chemicals were CYP inducers. These comparisons show that none of the above assays is alone sufficient for reliable identification of CAR ligands, and therefore, robust strategies should be based on tiered reporter gene, nuclear translocation and other assays.

Cross-activation of PXR is often seen among ligands of CAR discovered by screening programs (Lynch et al., 2019; Keminer et al., 2019) suggesting that PXR counterscreens should be included early in the discovery process. Even though many CAR-activating chemicals can activate multiple NRs (Küblbeck et al., 2020), it must be noted that the candidate CAR ligands have been tested for PXR and AhR only (e.g., Küblbeck et al., 2011a; Smutny et al., 2016; Liang et al., 2019; Marx-Stoelting et al., 2020) and only rarely for activation of other NRs (Maglich et al., 2003; Toporova et al., 2020) or with CAR from other species (Kublbeck et al., 2016; Pinne et al., 2016). 
Metabolism of the test compounds in the cells can create assignment problems. For instance, the antibacterial triclosan was first reported as an inverse agonist of hCAR 1 and a weak agonist of hCAR3 in full-length NR reporter gene assays (Paul et al., 2013). It proved to be an agonist in full-length mouse CAR, inactive in GAL4-CAR reporter gene assays but able to induce CYP2B10 mRNA in wild-type but not in CAR null mouse livers (Yueh et al., 2014). Later studies showed that triclosan is actually metabolized in hepatocytes to a more lipophilic and potent CAR agonist than the parent compound (Ashrap et al., 2017). Another example is the finding that the CAR inverse agonist PK11195 induces CYP2B6 in primary human hepatocytes. This could be rationalized by the fact that many CAR inverse agonists including PK11195 are also PXR agonists (Küblbeck et al., 2011b). However, PK11195 can activate CYP2B6 expression in PXR-knockout HepaRG cells, which was explained by CYP3A4catalyzed N-demethylation of PK1195 to a potent CAR agonist (Mackowiak et al., 2017). In summary, the lack or presence of metabolism may mask or change induction potential of the test compounds.

Finally, we do not yet have a test system that captures all or most aspects of indirect CAR activation. So far, a small number of compounds such as PB, flavonoids, chlordane, transnonachlor and two polychlorinated biphenyls have been shown to act by competitive inhibitory binding of the EGF receptor (Table 2; Mutoh et al., 2013; Carazo et al., 2015; Mackowiak and Wang, 2016; Hardesty et al., 2018). In addition, inhibition of EGF signalling can also take place via inhibition of the EGF receptor kinase or its downstream mediators. Mechanisms additional to EGF receptor inhibition can also take place as shown by teriflunomide-elicited upregulation (Carazo et al., 2018) and EGF-mediated repression of CAR expression (de Boussac et al., 2018). There are reports in which both CAR and its CYP target expressions are increased (Pascussi et al., 2000; Ayed-Boussema et al., 2012; Toporova and Balaguer, 2020), or CAR activity can be decreased (Yang et al., 2014) in 
response to xenobiotic exposure. Recently, 3D cultures of HepG2 cells were reported to retain CAR in the cytoplasm and respond to PB as in primary hepatocytes (Yokobori et al., 2019), perhaps providing a useful system to investigate mechanisms of indirect CAR activation. Finally, changes in CAR phosphorylation have not been often assessed. There is much to be learned about CAR phosphorylation at sites other than the residue T38, and especially about how CAR activity could be regulated by phosphorylation in the nucleus (Negishi et al., 2020).

In conclusion, searching for CAR ligands has become a highly complicated process extending beyond the simple agonist-elicited receptor activation. Multiple signalling pathways intersect at CAR. Therefore, their accurate evaluation requires several complementary assays and control experiments to exclude off-target effects, highlight ligandspecific coactivator recruitment or detect changes in CAR phosphorylation status (Table 4).

\section{Acknowledgements}

P.H. dedicates this minireview to his postdoctoral mentor and long-time collaborator Dr. Masahiko Negishi at NIEHS on the occasion of his retirement. His wide and lasting contributions to understand mechanisms of CYP expression, substrate specificities of CYPs, sulfotransferases, and molecular mechanisms of CAR and PXR activation will always be remembered and appreciated. The hard work by current and past postdocs and Ph.D. students at the Honkakoski laboratory are acknowledged. Dr. Tuomo Laitinen is thanked for molecular modeling for Figure 2.

\section{Authorship contribution}

Wrote or contributed to the writing of the manuscript: P.H. 


\section{References}

Ashrap P, Zheng G, Wan Y, Li T, Hu W, Li W, Zhang H, Zhang Z and Hu J (2017)

Discovery of a widespread metabolic pathway within and among phenolic xenobiotics. Proc Natl Acad Sci U S A 114: 6062-6067.

Auerbach SS, Stoner MA, Su S and Omiecinski CJ (2005) Retinoid X receptor-alphadependent transactivation by a naturally occurring structural variant of human constitutive androstane receptor (NR1I3). Mol Pharmacol 68: 1239-1253.

Auerbach SS, DeKeyser JG, Stoner MA and Omiecinski CJ (2007) CAR2 displays unique ligand binding and RXRalpha heterodimerization characteristics. Drug Metab Dispos 35: 428-439.

Ayed-Boussema I, Pascussi JM, Maurel P, Bacha H and Hassen W (2012) Effect of aflatoxin B1 on nuclear receptors PXR, CAR, and AhR and their target cytochromes P450 mRNA expression in primary cultures of human hepatocytes. Int J Toxicol 31: 86-93.

Bae SDW, Nguyen R, Qiao L and George J (2021) Role of the constitutive androstane receptor (CAR) in human liver cancer. Biochim Biophys Acta Rev Cancer 1875: 188516.

Baes M, Gulick T, Choi HS, Martinoli MG, Simha D and Moore DD (1994) A new orphan member of the nuclear hormone receptor superfamily that interacts with a subset of retinoic acid response elements. Mol Cell Biol 14: 1544-1552.

Berthier A, Staels B and Lefebvre P (2021) An optimized protocol with a stepwise approach to identify specific nuclear receptor ligands from cultured mammalian cells. STAR Protocols 2: 100658 . 
Buchman CD, Chai SC and Chen T (2018) A current structural perspective on PXR and CAR in drug metabolism. Expert Opin Drug Metab Toxicol 14: 635-647.

Burk O, Piedade R, Ghebreghiorghis L, Fait JT, Nussler AK, Gil JP, Windshügel B and Schwab M (2012) Differential effects of clinically used derivatives and metabolites of artemisinin in the activation of constitutive androstane receptor isoforms. Br J Pharmacol 167: 666-681.

Cai X, Young GM and Xie W (2021) The xenobiotic receptors PXR and CAR in liver physiology, an update. Biochim Biophys Acta Mol Basis Dis 1867: 166101.

Carazo Fernández A, Smutny T, Hyrsová L, Berka K and Pavek P (2015) Chrysin, baicalein and galangin are indirect activators of the human constitutive androstane receptor (CAR). Toxicol Lett 233: 68-77.

Carazo A, Dusek J, Holas O, Skoda J, Hyrsova L, Smutny T, Soukup T, Dosedel M and Pávek P (2018) Teriflunomide is an indirect human constitutive androstane receptor (CAR) activator interacting with epidermal growth factor (EGF) signaling. Front Pharmacol 9: 993.

Chai SC, Cherian MT, Wang YM and Chen T (2016) Small-molecule modulators of PXR and CAR. Biochim Biophys Acta 1859: 1141-1154.

Chai SC, Lin W, Li Y and Chen T (2019) Drug discovery technologies to identify and characterize modulators of the pregnane $\mathrm{X}$ receptor and the constitutive androstane receptor. Drug Discov Today 24: 906-915.

Chen T, Tompkins LM, Li L, Li H, Kim G, Zheng Y and Wang H (2010) A single amino acid controls the functional switch of human constitutive androstane receptor (CAR) 1 to the xenobiotic-sensitive splicing variant CAR3. J Pharmacol Exp Ther 332: 106-115. 
Cherian MT, Chai SC, Wright WC, Singh A, Alexandra Casal M, Zheng J, Wu J, Lee RE, Griffin PR and Chen T (2018) CINPA1 binds directly to constitutive androstane receptor and inhibits its activity. Biochem Pharmacol 152: 211-223.

Choi HS, Chung M, Tzameli I, Simha D, Lee YK, Seol W and Moore DD (1997) Differential transactivation by two isoforms of the orphan nuclear hormone receptor CAR. J Biol Chem 272: $23565-23571$.

Clifford T, Acton JP, Cocksedge SP, Bowden Davies KA and Bailey SJ (2021) The effect of dietary phytochemicals on nuclear factor erythroid 2-related factor 2 (Nrf2) activation: a systematic review of human intervention trials. Mol Biol Rep 48: 1745-1761.

Dahlin JL, Nissink JW, Strasser JM, Francis S, Higgins L, Zhou H, Zhang Z and Walters MA (2015) PAINS in the assay: chemical mechanisms of assay interference and promiscuous enzymatic inhibition observed during a sulfhydryl-scavenging HTS. J Med Chem 58: 20912113.

Daujat-Chavanieu M and Gerbal-Chaloin S (2020) Regulation of CAR and PXR expression in health and disease. Cells 9: 2395.

de Boussac H, Gondeau C, Briolotti P, Duret C, Treindl F, Römer M, Fabre JM, Herrero A, Ramos J, Maurel P, Templin M, Gerbal-Chaloin S and Daujat-Chavanieu M (2018) Epidermal growth factor represses constitutive androstane receptor expression in primary human hepatocytes and favors regulation by pregnane X receptor. Drug Metab Dispos 46: 223-236.

DeKeyser JG, Laurenzana EM, Peterson EC, Chen T and Omiecinski CJ (2011) Selective phthalate activation of naturally occurring human constitutive androstane receptor splice variants and the pregnane X receptor. Toxicol Sci 120: 381-391. 
Forman BM, Tzameli I, Choi HS, Chen J, Simha D, Seol W, Evans RM and Moore DD (1998) Androstane metabolites bind to and deactivate the nuclear receptor CAR-beta. Nature 395: 612-615.

Hardesty JE, Al-Eryani L, Wahlang B, Falkner KC, Shi H, Jin J, Vivace BJ, Ceresa BP, Prough RA and Cave MC (2018) Epidermal growth factor receptor signaling disruption by endocrine and metabolic disrupting chemicals. Toxicol Sci 162: 622-634.

Hazafa A, Iqbal MO, Javaid U, Tareen MBK, Amna D, Ramzan A, Piracha S and Naeem M (2021) Inhibitory effect of polyphenols (phenolic acids, lignans, and stilbenes) on cancer by regulating signal transduction pathways: a review. Clin Transl Oncol. doi: 10.1007/s12094021-02709-3.

Hoffart E, Ghebreghiorghis L, Nussler AK, Thasler WE, Weiss TS, Schwab M and Burk O (2012) Effects of atorvastatin metabolites on induction of drug-metabolizing enzymes and membrane transporters through human pregnane X receptor. Br J Pharmacol 165: 15951608.

Ho P, Yue K, Pandey P, Breault L, Harbinski F, McBride AJ, Webb B, Narahari J, Karassina N, Wood KV, Hill A and Auld DS (2013) Reporter enzyme inhibitor study to aid assembly of orthogonal reporter gene assays. ACS Chem Biol 8: 1009-1017.

Honkakoski P and Negishi M (1997) Characterization of a phenobarbital-responsive enhancer module in mouse P450 Cyp2b10 gene. J Biol Chem 272: 14943-14949.

Honkakoski P, Zelko I, Sueyoshi T and Negishi M (1998a) The nuclear orphan receptor CAR-retinoid X receptor heterodimer activates the phenobarbital-responsive enhancer module of the CYP2B gene. Mol Cell Biol 18: 5652-5658. 
Honkakoski P, Moore R, Washburn KA and Negishi M (1998b) Activation by diverse xenochemicals of the 51-base pair phenobarbital-responsive enhancer module in the CYP2B10 gene. Mol Pharmacol 53: 597-601.

Honkakoski P, Palvimo JJ, Penttilä L, Vepsäläinen J and Auriola S (2004) Effects of triaryl phosphates on mouse and human nuclear receptors. Biochem Pharmacol 67: 97-106.

Hsu CW, Hsieh JH, Huang R, Pijnenburg D, Khuc T, Hamm J, Zhao J, Lynch C, van Beuningen R, Chang X, Houtman R and Xia M (2016) Differential modulation of FXR activity by chlorophacinone and ivermectin analogs. Toxicol Appl Pharmacol 313: 138-148.

Huang W, Zhang J, Wei P, Schrader WT and Moore DD (2004) Meclizine is an agonist ligand for mouse constitutive androstane receptor (CAR) and an inverse agonist for human CAR. Mol Endocrinol 18: 2402-2408.

Ikeda S, Kurose K, Jinno H, Sai K, Ozawa S, Hasegawa R, Komamura K, Kotake T, Morishita H, Kamakura S, Kitakaze M, Tomoike H, Tamura T, Yamamoto N, Kunitoh H, Yamada Y, Ohe Y, Shimada Y, Shirao K, Kubota K, Minami H, Ohtsu A, Yoshida T, Saijo N, Saito Y and Sawada J (2005) Functional analysis of four naturally occurring variants of human constitutive androstane receptor. Mol Genet Metab 86: 314-319.

Imai J, Yamazoe Y and Yoshinari K (2013) Novel cell-based reporter assay system using epitope-tagged protein for the identification of agonistic ligands of constitutive androstane receptor (CAR). Drug Metab Pharmacokinet 28: 290-298.

Jeske J, Windshügel B, Thasler WE, Schwab M and Burk O (2017) Human pregnane X receptor is activated by dibenzazepine carbamate-based inhibitors of constitutive androstane receptor. Arch Toxicol 91: 2375-2390. 
Jyrkkärinne J, Mäkinen J, Gynther J, Savolainen H, Poso A and Honkakoski P (2003)

Molecular determinants of steroid inhibition for the mouse constitutive androstane receptor. $J$ Med Chem 46: 4687-4695.

Jyrkkärinne J, Windshügel B, Mäkinen J, Ylisirniö M, Peräkylä M, Poso A, Sippl W and Honkakoski P (2005) Amino acids important for ligand specificity of the human constitutive androstane receptor. J Biol Chem 280: 5960-5971.

Kanno Y and Inouye Y (2010) A consecutive three alanine residue insertion mutant of human CAR: a novel CAR ligand screening system in HepG2 cells. J Toxicol Sci 35: 515-525.

Karczewski KJ, Francioli LC, Tiao G, Cummings BB, Alföldi J, Wang Q, Collins RL, Laricchia KM, Ganna A, Birnbaum DP, Gauthier LD, Brand H, Solomonson M, Watts NA, Rhodes D, Singer-Berk M, England EM, Seaby EG, Kosmicki JA, Walters RK, Tashman K, Farjoun Y, Banks E, Poterba T, Wang A, Seed C, Whiffin N, Chong JX, Samocha KE, Pierce-Hoffman E, Zappala Z, O'Donnell-Luria AH, Minikel EV, Weisburd B, Lek M, Ware JS, Vittal C, Armean IM, Bergelson L, Cibulskis K, Connolly KM, Covarrubias M, Donnelly S, Ferriera S, Gabriel S, Gentry J, Gupta N, Jeandet T, Kaplan D, Llanwarne C, Munshi R, Novod S, Petrillo N, Roazen D, Ruano-Rubio V, Saltzman A, Schleicher M, Soto J, Tibbetts K, Tolonen C, Wade G, Talkowski ME, Genome Aggregation Database Consortium, Neale BM, Daly MJ and MacArthur DG (2020) The mutational constraint spectrum quantified from variation in 141,456 humans. Nature 581: 434-443.

Kato H (2020) Computational prediction of cytochrome P450 inhibition and induction. Drug Metab Pharmacokinet 35: 30-44. 
Kawamoto T, Sueyoshi T, Zelko I, Moore R, Washburn K and Negishi M (1999)

Phenobarbital-responsive nuclear translocation of the receptor CAR in induction of the CYP2B gene. Mol Cell Biol 19: 6318-6322.

Keminer O, Windshügel B, Essmann F, Lee SML, Schiergens TS, Schwab M and Burk O (2019) Identification of novel agonists by high-throughput screening and molecular modelling of human constitutive androstane receptor isoform 3. Arch Toxicol 93: 2247-2264.

Kliewer SA, Moore JT, Wade L, Staudinger JL, Watson MA, Jones SA, McKee DD, Oliver BB, Willson TM, Zetterström RH, Perlmann and Lehmann JM (1998) An orphan nuclear receptor activated by pregnanes defines a novel steroid signaling pathway. Cell 92: 73-82.

Kobashigawa Y, Namikawa M, Sekiguchi M, Inada Y, Yamauchi S, Kimoto Y, Okazaki K, Toyota Y, Sato T and Morioka H (2021) Expression, purification and characterization of CAR/NCOA-1 tethered protein in E. coli using maltose-binding protein fusion tag and gelatinized corn starch. Biol Pharm Bull 44: 125-130.

Küblbeck J, Jyrkkärinne J, Poso A, Turpeinen M, Sippl W, Honkakoski P and Windshügel B (2008) Discovery of substituted sulfonamides and thiazolidin-4-one derivatives as agonists of human constitutive androstane receptor. Biochem Pharmacol 76: 1288-1297.

Küblbeck J, Laitinen T, Jyrkkärinne J, Rousu T, Tolonen A, Abel T, Kortelainen T, Uusitalo J, Korjamo T, Honkakoski P and Molnár F (2011a) Use of comprehensive screening methods to detect selective human CAR activators. Biochem Pharmacol 82: 1994-2007.

Küblbeck J, Jyrkkärinne J, Molnár F, Kuningas T, Patel J, Windshügel B, Nevalainen T, Laitinen T, Sippl W, Poso A and Honkakoski P (2011b) New in vitro tools to study human constitutive androstane receptor (CAR) biology: discovery and comparison of human CAR inverse agonists. Mol Pharm 8: 2424-2433. 
Küblbeck J, Zancanella V, Prantner V, Molnár F, Squires EJ, Dacasto M, Honkakoski P and Giantin M (2016) Characterization of ligand-dependent activation of bovine and pig constitutive androstane (CAR) and pregnane $\mathrm{X}$ receptors (PXR) with interspecies comparisons. Xenobiotica 46: 200-210.

Küblbeck J, Niskanen J and Honkakoski P (2020) Metabolism-disrupting chemicals and the constitutive androstane receptor CAR. Cells 9: 2306.

Lake BG (2018) Human relevance of rodent liver tumour formation by constitutive androstane receptor (CAR) activators. Toxicol Res (Camb) 7: 697-717.

Lamba J, Lamba V and Schuetz E (2005) Genetic variants of PXR (NR1I2) and CAR (NR1I3) and their implications in drug metabolism and pharmacogenetics. Curr Drug Metab 6: $369-383$.

Lau AJ, Yang G, Rajaraman G, Baucom CC and Chang TK (2011) Differential effect of meclizine on the activity of human pregnane $\mathrm{X}$ receptor and constitutive androstane receptor. J Pharmacol Exp Ther 336: 816-826.

Li H, Chen T, Cottrell J and Wang H (2009) Nuclear translocation of adenoviral-enhanced yellow fluorescent protein-tagged-human constitutive androstane receptor (hCAR): a novel tool for screening hCAR activators in human primary hepatocytes. Drug Metab Dispos 37: 1098-1106.

Li D, Mackowiak B, Brayman TG, Mitchell M, Zhang L, Huang SM and Wang H (2015) Genome-wide analysis of human constitutive androstane receptor (CAR) transcriptome in wild-type and CAR-knockout HepaRG cells. Biochem Pharmacol 98: 190-202. 
Liang D, Li L, Lynch C, Diethelm-Varela B, Xia M, Xue F and Wang H (2019) DL5050, a selective agonist for the human constitutive androstane receptor. ACS Med Chem Lett 10: 1039-1044.

Lin W, Bwayi M, Wu J, Li Y, Chai SC, Huber AD and Chen T (2020) CITCO directly binds to and activates human pregnane X receptor. Mol Pharmacol 97: 180-190.

Lynch C, Pan Y, Li L, Ferguson SS, Xia M, Swaan PW and Wang H (2013) Identification of novel activators of constitutive androstane receptor from FDA-approved drugs by integrated computational and biological approaches. Pharm Res 30: 489-501.

Lynch C, Zhao J, Huang R, Xiao J, Li L, Heyward S, Xia M and Wang H (2015) Quantitative high-throughput identification of drugs as modulators of human constitutive androstane receptor. Sci Rep 5: 10405.

Lynch C, Mackowiak B, Huang R, Li L, Heyward S, Sakamuru S, Wang H and Xia M (2019) Identification of modulators that activate the constitutive androstane receptor from the Tox 21 10K compound library. Toxicol Sci 167: 282-292.

Mackowiak B and Wang H (2016) Mechanisms of xenobiotic receptor activation: Direct vs. indirect. Biochim Biophys Acta 1859: 1130-1140.

Mackowiak B, Li L, Welch MA, Li D, Jones JW, Heyward S, Kane MA, Swaan PW and Wang H (2017) Molecular basis of metabolism-mediated conversion of PK11195 from an antagonist to an agonist of the constitutive androstane receptor. Mol Pharmacol 92: 75-87.

Mackowiak B, Li L, Lynch C, Ziman A, Heyward S, Xia M and Wang H (2019) Highcontent analysis of constitutive androstane receptor (CAR) translocation identifies mosapride citrate as a CAR agonist that represses gluconeogenesis. Biochem Pharmacol 168: 224-236. 
Maglich JM, Parks DJ, Moore LB, Collins JL, Goodwin B, Billin AN, Stoltz CA, Kliewer SA, Lambert MH, Willson TM and Moore JT (2003) Identification of a novel human constitutive androstane receptor (CAR) agonist and its use in the identification of CAR target genes. J Biol Chem 278: 17277-17283.

Mäkinen J, Frank C, Jyrkkärinne J, Gynther J, Carlberg C and Honkakoski P (2002) Modulation of mouse and human phenobarbital-responsive enhancer module by nuclear receptors. Mol Pharmacol 62: 366-378.

Mäkinen J, Reinisalo M, Niemi K, Viitala P, Jyrkkärinne J, Chung H, Pelkonen O and Honkakoski P (2003) Dual action of oestrogens on the mouse constitutive androstane receptor. Biochem J 376: 465-472.

Marx-Stoelting P, Knebel C and Braeuning A (2020) The connection of azole fungicides with xeno-sensing nuclear receptors, drug metabolism and hepatotoxicity. Cells 9: 1192.

Mbatchi LC, Brouillet JP and Evrard A (2018) Genetic variations of the xenoreceptors NR1I2 and NR1I3 and their effect on drug disposition and response variability.

Pharmacogenomics 19: 61-77.

Molnár F, Küblbeck J, Jyrkkärinne J, Prantner V and Honkakoski P (2013) An update on the constitutive androstane receptor (CAR). Drug Metabol Drug Interact 28: 79-93.

Moore LB, Maglich JM, McKee DD, Wisely B, Willson TM, Kliewer SA, Lambert MH and Moore JT (2002) Pregnane X receptor (PXR), constitutive androstane receptor (CAR), and benzoate $\mathrm{X}$ receptor (BXR) define three pharmacologically distinct classes of nuclear receptors. Mol Endocrinol 16: 977-986. 
Murayama N, van Beuningen R, Suemizu H, Guillouzo CG, Shibata N, Yajima K, Utoh M, Shimizu M, Chesné C, Nakamura M, Guengerich FP, Houtman R and Yamazaki H (2014) Thalidomide increases human hepatic cytochrome P450 3A enzymes by direct activation of the pregnane X receptor. Chem Res Toxicol 27: 304-308.

Mutoh S, Sobhany M, Moore R, Perera L, Pedersen L, Sueyoshi T and Negishi M (2013) Phenobarbital indirectly activates the constitutive active androstane receptor (CAR) by inhibition of epidermal growth factor receptor signaling. Sci Signal 6: ra31.

Negishi M (2017) Phenobarbital meets phosphorylation of nuclear receptors. Drug Metab Dispos 45: 532-539.

Negishi M, Kobayashi K, Sakuma T and Sueyoshi T (2020) Nuclear receptor phosphorylation in xenobiotic signal transduction. J Biol Chem 295: 15210-15225.

Nudischer R, Renggli K, Bertinetti-Lapatki C, Hoflack JC, Flint N, Sewing S, Pedersen L, Schadt S, Higgins LG, Vardy A, Lenz B, Gand L, Boess F, Elcombe BM, Hierlemann A and Roth AB (2020) Combining in vivo and organotypic in vitro approaches to assess the human relevance of basimglurant (RG7090), a potential CAR activator. Toxicol Sci 176: 329-342.

Ochsner SA, Tsimelzon A, Dong J, Coarfa C and McKenna NJ (2016) A reference transcriptome for constitutive androstane receptor and pregnane $\mathrm{X}$ receptor xenobiotic signaling. Mol Endocrinol 30: 937-948.

Okuda Y, Kushida M, Kikumoto H, Nakamura Y, Higuchi H, Kawamura S, Cohen SM, Lake BG and Yamada T (2017) Evaluation of the human relevance of the constitutive androstane receptor-mediated mode of action for rat hepatocellular tumor formation by the synthetic pyrethroid momfluorothrin. J Toxicol Sci 42: 773-788. 
Omiecinski CJ, Coslo DM, Chen T, Laurenzana EM and Peffer RC (2011) Multi-species analyses of direct activators of the constitutive androstane receptor. Toxicol Sci 123: 550562.

Pascussi JM, Gerbal-Chaloin S, Fabre JM, Maurel P and Vilarem MJ (2000) Dexamethasone enhances constitutive androstane receptor expression in human hepatocytes: consequences on cytochrome P450 gene regulation. Mol Pharmacol 58: 1441-1450.

Paul KB, Thompson JT, Simmons SO, Vanden Heuvel JP and Crofton KM (2013) Evidence for triclosan-induced activation of human and rodent xenobiotic nuclear receptors. Toxicol In Vitro 27: 2049-2060.

Pinne M, Ponce E and Raucy JL (2016) Transactivation assays to assess canine and rodent pregnane $\mathrm{X}$ receptor (PXR) and constitutive androstane receptor (CAR) activation. PLoS One 11: $\mathrm{e} 0164642$.

Poutiainen PK, Palvimo JJ, Hinkkanen AE, Valkonen A, Väisänen TK, Laatikainen R and Pulkkinen JT (2013) Discovery of 5-benzyl-3-phenyl-4,5-dihydroisoxazoles and 5-benzyl-3phenyl-1,4,2-dioxazoles as potent firefly luciferase inhibitors. J Med Chem 56: 1064-1073.

Prantner V, Cinnamon Y, Küblbeck J, Molnár F and Honkakoski P (2018) Functional characterization of a novel variant of the constitutive androstane receptor (CAR, NR1I3). Nucl Receptor Res 5: 101386.

Preiss LC, Liu R, Hewitt P, Thompson D, Georgi K, Badolo L, Lauschke WM and Petersson C (2021) Deconvolution of cytochrome P450 induction mechanisms in HepaRG nuclear hormone receptor knockout cells. Drug Metab Dispos 49: 668-678. 
Raucy JL and Lasker JM (2013) Cell-based systems to assess nuclear receptor activation and their use in drug development. Drug Metab Rev 45: 101-109.

Reschly EJ and Krasowski MD (2006) Evolution and function of the NR1I nuclear hormone receptor subfamily (VDR, PXR, and CAR) with respect to metabolism of xenobiotics and endogenous compounds. Curr Drug Metab 7: 349-365.

Režen T, Hafner M, Kortagere S, Ekins S, Hodnik V and Rozman D (2017) Rosuvastatin and atorvastatin are ligands of the human constitutive androstane receptor/retinoid $\mathrm{X}$ receptor alpha complex. Drug Metab Dispos 45: 974-976.

Scheer N and Wolf CR (2014) Genetically humanized mouse models of drug metabolizing enzymes and transporters and their applications. Xenobiotica 44: 96-108.

Sharma D, Lau AJ, Sherman MA and Chang TK (2015) Differential activation of human constitutive androstane receptor and its SV23 and SV24 splice variants by rilpivirine and etravirine. Br J Pharmacol 172: 1263-1276.

Skoda J, Dusek J, Drastik M, Stefela A, Dohnalova K, Chalupsky K, Smutny T, Micuda S, Gerbal-Chaloin S and Pavek P (2020) Diazepam promotes translocation of human constitutive androstane receptor (CAR) via direct interaction with the ligand-binding domain. Cells 9: 2532.

Smutny T, Nova A, Drechslerová M, Carazo A, Hyrsova L, Hrušková ZR, Kuneš J, Pour M, Špulák M and Pavek P (2016) 2-(3-Methoxyphenyl)quinazoline derivatives: a new class of direct constitutive androstane receptor (CAR) agonists. J Med Chem 59: 4601-4610. 
Sueyoshi T, Kawamoto T, Zelko I, Honkakoski P and Negishi M (1999) The repressed nuclear receptor CAR responds to phenobarbital in activating the human $C Y P 2 B 6$ gene. $J$ Biol Chem 274: 6043-6046.

Suino K, Peng L, Reynolds R, Li Y, Cha JY, Repa JJ, Kliewer SA and Xu HE (2004) The nuclear xenobiotic receptor CAR: structural determinants of constitutive activation and heterodimerization. Mol Cell 16: 893-905.

Tanaka N, Aoyama T, Kimura S and Gonzalez FJ (2017) Targeting nuclear receptors for the treatment of fatty liver disease. Pharmacol Ther 179: 142-157.

Toporova L and Balaguer P (2020) Nuclear receptors are the major targets of endocrine disrupting chemicals. Mol Cell Endocrinol 502: 110665.

Toporova L, Grimaldi M, Boulahtouf A and Balaguer P (2020) Assessing the selectivity of FXR, LXRs, CAR, and ROR $\gamma$ pharmaceutical ligands with reporter cell lines. Front Pharmacol 11: 1122.

Ueda A, Hamadeh HK, Webb HK, Yamamoto Y, Sueyoshi T, Afshari CA, Lehmann JM and Negishi M (2002) Diverse roles of the nuclear orphan receptor CAR in regulating hepatic genes in response to phenobarbital. Mol Pharmacol 61: 1-6.

Wahlang B, Falkner KC, Clair HB, Al-Eryani L, Prough RA, States JC, Coslo DM, Omiecinski CJ and Cave MC (2014) Human receptor activation by Aroclor 1260, a polychlorinated biphenyl mixture. Toxicol Sci 140: 283-297.

Wei P, Zhang J, Egan-Hafley M, Liang S and Moore DD (2000) The nuclear receptor CAR mediates specific xenobiotic induction of drug metabolism. Nature 407: 920-923. 
Willson TM and Kliewer SA (2002) PXR, CAR and drug metabolism. Nat Rev Drug Discov 1: 259-266.

Xu RX, Lambert MH, Wisely BB, Warren EN, Weinert EE, Waitt GM, Williams JD, Collins JL, Moore LB, Willson TM and Moore JT (2004) A structural basis for constitutive activity in the human CAR/RXRalpha heterodimer. Mol Cell 16: 919-928.

Yahfoufi N, Alsadi N, Jambi M and Matar C (2018) The immunomodulatory and antiinflammatory role of polyphenols. Nutrients 10: 1618 .

Yamamoto Y, Moore R, Goldsworthy TL, Negishi M and Maronpot RR (2004) The orphan nuclear receptor constitutive active/androstane receptor is essential for liver tumor promotion by phenobarbital in mice. Cancer Res 64: 7197-7200.

Yan J and Xie W (2016) A brief history of the discovery of PXR and CAR as xenobiotic receptors. Acta Pharm Sin B 6: 450-452.

Yang H, Garzel B, Heyward S, Moeller T, Shapiro P and Wang H (2014) Metformin represses drug-induced expression of CYP2B6 by modulating the constitutive androstane receptor signaling. Mol Pharmacol 85: 249-260.

Yao R, Yasuoka A, Kamei A, Kitagawa Y, Tateishi N, Tsuruoka N, Kiso Y, Sueyoshi T, Negishi M, Misaka T and Abe K (2010) Dietary flavonoids activate the constitutive androstane receptor (CAR). J Agric Food Chem 58: 2168-73.

Yokobori K, Azuma I, Chiba K, Akita H, Furihata T and Kobayashi K (2019) Indirect activation of constitutive androstane receptor in three-dimensionally cultured HepG2 cells. Biochem Pharmacol 168: 26-37. 
Yueh MF, Taniguchi K, Chen S, Evans RM, Hammock BD, Karin M and Tukey RH (2014)

The commonly used antimicrobial additive triclosan is a liver tumor promoter. Proc Natl Acad Sci U S A 111: 17200-17205. 


\section{Footnotes}

\section{Financial support}

P.H. is partially supported by Academy of Finland [grant 332660] and European Union's Horizon 2020 research and innovation programme [grant 825762]. P.H. acknowledges past financial support to him and his students from the Academy of Finland, National Agency for Technology and Innovation, FinPharma Doctoral program and the Finnish Cultural Foundation for research cited in the manuscript.

\section{Financial disclosure}

No author has an actual or perceived conflict of interest with the contents of this article. 


\section{Figure legends}

Figure 1. Activation mechanisms of CAR. In the indirect activation, PB acts as an antagonist of EGF receptor which results in dephosphorylation of phospho-ERK and dephosphorylation of RACK (A). Both PB and directly acting CAR ligands can dissociate the cytoplasmic complex that contains CAR as a phosphorylated homodimer. The monomeric CAR associates with RACK and PP2A leading to dephosphorylation of CAR (B).

Dephosphorylated CAR is translocated into the nucleus which heterodimerization with RXR, binding to DNA response elements such as PBREM and recruitment of NR coactivators culminates in increased expression of CYP and other genes (C). It should be noted that details of these mechanisms have formally been demonstrated only for some CAR activators.

Figure 2. A model of the agonist-bound CAR ligand-binding domain. Helices are displayed with labeled cylinders starting from the LBD N-terminus (H1 to H12). The activation helix (H12) is shown in blue and the NR-binding coactivator peptide (CoA) in green. The CAR agonist CITCO is shown in gold and the crucial amino acid residues in grey licorice (F161, N165, F234, Y326). The light grey "cloud" in the background and near H6 is due to the $\beta$-sheet structure of the CAR LBD. The model was created with Discovery Studio (BIOVIA, Dassault Systèmes, San Diego, CA) using the reported crystal structure of CAR/RXR heterodimer bound with SRC1 peptide, fatty acid and CITCO (1XVP; rcsb.org). 
Table 1. Selection of recent review articles on characteristics and functions of CAR.

\section{Topic}

CAR ligand-binding domain structures

Computational modeling

Genetic variants

CAR phosphorylation and dimerization

Direct and indirect activation mechanisms

Small-molecule modulators

Main assay technologies

Developmental and tissue expression

Role in liver physiology and disease

Role in endocrine disruption

Role in liver tumor formation

\section{References}

Buchman et al., 2018

Kato, 2020

Mbatchi et al., 2018

Negishi, 2017; Negishi et al., 2020

Mackowiak and Wang, 2016

Chai et al., 2016

Chai et al., 2019

Daujat-Chavanieu and Gerbal-Chaloin, 2020

Tanaka et al., 2017; Cai et al., 2021

Küblbeck et al., 2020; Toporova and

Balaguer, 2020

Lake, 2018; Bae et al., 2021 
Table 2. Established indirect activators, direct agonists and inverse agonists of human CAR.

\section{Modulator classes}

Indirect activators

Selective agonists

Inverse agonists

\section{Chemicals}

PB, teriflunomide, phenytoin*, some flavonoids*,

polychlorinated biphenyls*

DL5050, rimcazole, CITCO $\dagger$, clemizole $\dagger$

PK11195†, S07662†, CINPA1†, clotrimazole $\S$
References

Mutoh et al., 20䱢3; Carazo et al., 2018; Chai et al., $\underset{\substack{0 \\ 0 \rightarrow 0}}{0.07}$

2016; Carazo Fё̆rnandes et al., 2015; Yao et al., 2010;

Hardesty et al., 爱018; Molnár et al. 2013

$$
\begin{aligned}
& \text { 总 } \\
& \text { 总 } \\
& \text { 号 }
\end{aligned}
$$

Liang et al., 20 9y 9 ; Lynch et al., 2019; Maglich et al., 2003; Lin et al.

Cherian et al., 2018; Küblbeck et al., 2011;

Jeske et al., 2017; Toporova et al., 2020

* some evidence for both indirect and direct activation

$\dagger$ reports indicate additionally activation of PXR

$\S$ reports indicate variable results from agonist to inactive to inverse agonist 
Table 3. Proposed strategy in identifying CAR modulators.

\section{Assay type \\ Reporter gene assay*† with full-length or LBD constructs with or without competitive inverse agonist}

Cell-based two-hybrid assays $* \dagger$

Cell-free two-hybrid or binding studies $\uparrow$

Nuclear translocation assay

RNA expression studies in hepatic cells or in vivo

\section{Interpretation and follow-up studie}

Changes in reporter activity $(\uparrow \downarrow)$ : ago鱼ists and inverse agonists identified; replication studies; verification by the-hybrid or binding assays; PXR

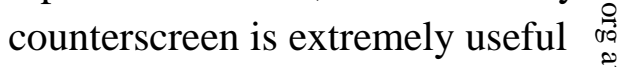

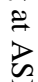

Changes in reporter activity $(\uparrow)$ : iden 算ication of respective coactivator or corepressor; indication of ligand-CR interaction; supported by binding assays

Changes in readout $(\uparrow)$ : identificationsog direct binding to CAR; may not distinguish between agonists and in

$$
\text { 芯 }
$$

Changes in cytoplasmic/nuclear staining of tagged CAR: detection of CAR indirect activators; requires secondary analysis by reporter gene or twohybrid systems; analysis of contributing signalling pathways useful

Increase in CAR target gene mRNAs $(\uparrow)$ : verification in cells lacking CAR (knockout or siRNA knockdown in cells, knockout animals, humanized mice) analysis of PXR target genes useful

* supported by competitive displacement studies (agonist versus inverse agonist) in the same system

$\dagger$ supported by molecular modelling studies for directly binding agonists/inverse agonists 
Table 4. Key methods, problems and potential solutions in identification of CAR modulators.

\section{Typical assay}

CAR reporter gene assays and two-hybrid assays

RNA expression assays in hepatic cells or liver tissues

All assays
Problems

High basal activity

Dynamic range

Off-target effects

Off-target effects

Reproducibility

Solubility

\section{Potential solutions}

Useful for inverse agonists; agonist de्: agonist, use of a CAR variant or a cill line with low basal activity

Selection of cell line; choice of positi倠 controls; selection of coregulators in two-hybrid systems

突

Screen for inhibition of reporter enzy PXR activation due to common target genes

กั

Measure responses of CAR (CYP2B) and PXR (CYP3A) target genes; check for effects on CAR expression and phosphorylation; verification in wildtype and knock-out cells or humanized animals; use of CAR inverse agonists is problematic as they are often PXR agonists

Positive and negative controls, repeated measurement; formal validation of the assay recommended

Solubility measurements in appropriate medium/buffer, increase vehicle content in cell-free systems 
A.

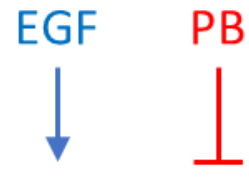

EGF receptor

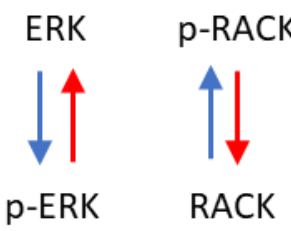

B.
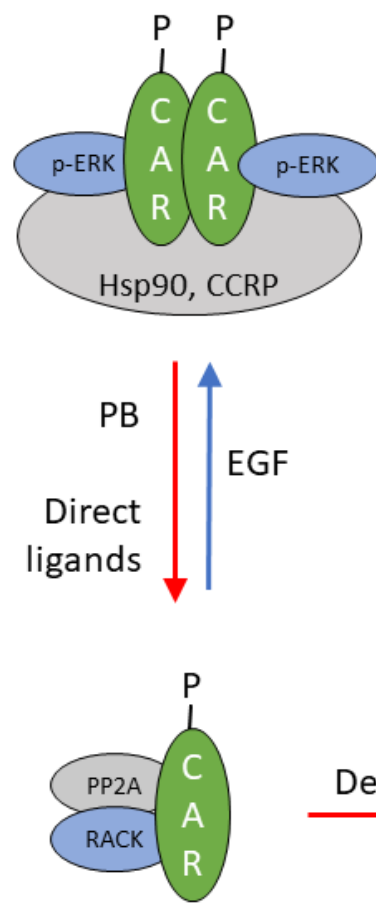

C.

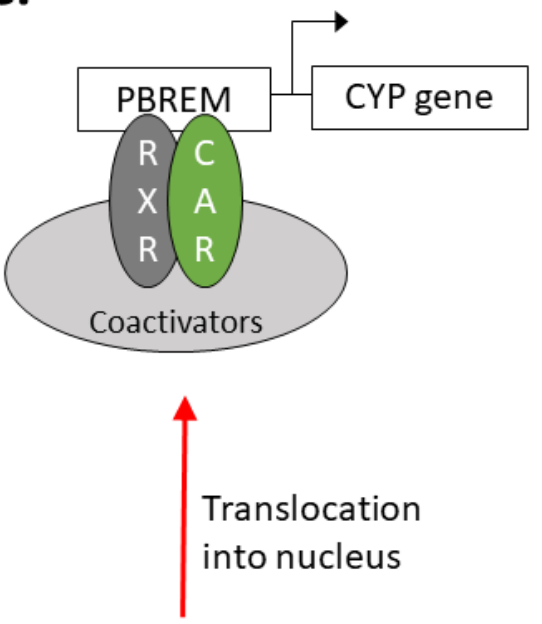

Figure 1 
Figure 2

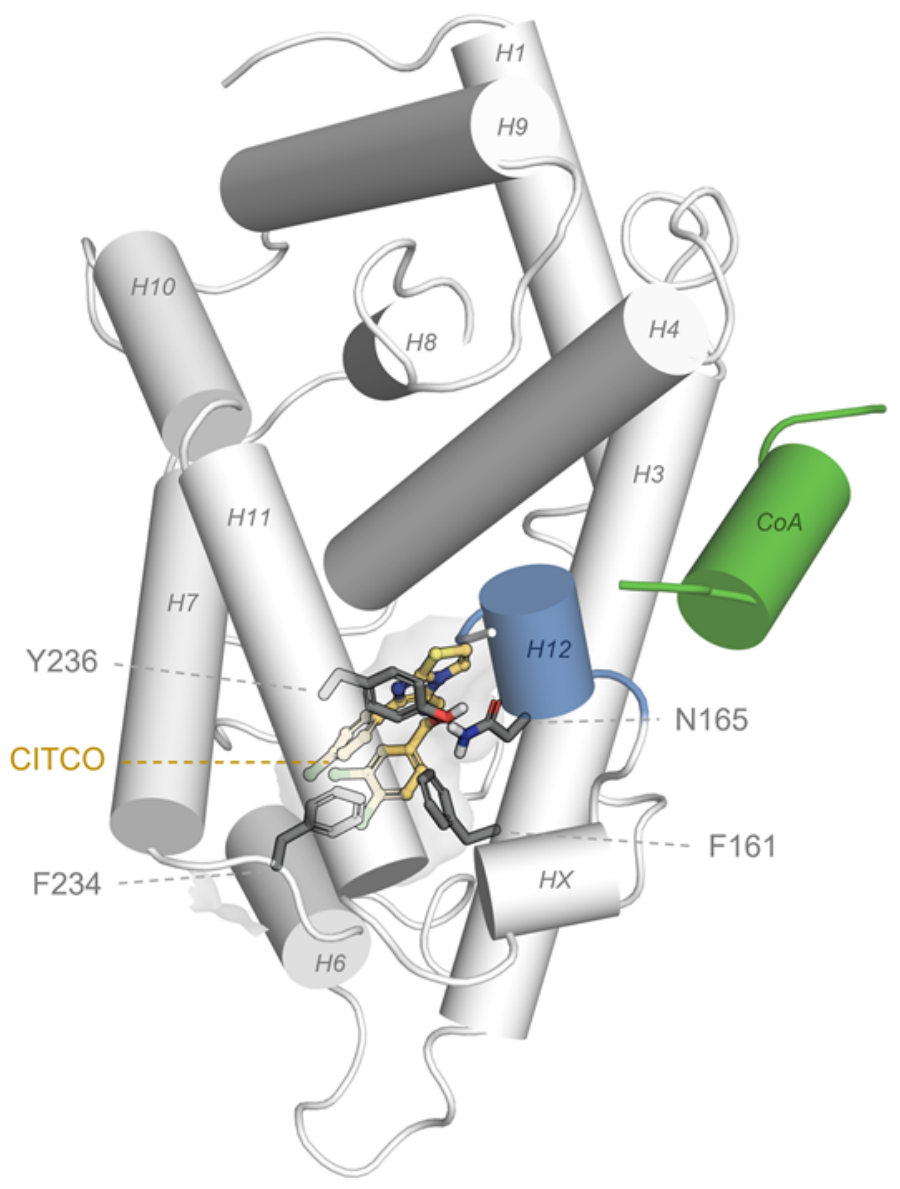

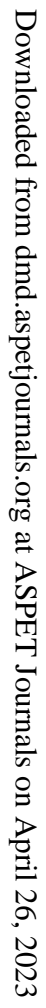

